\title{
Gastric cancer in the East and West: what should we learn from each other?
}

\author{
Giovanni de Manzoni ${ }^{1}$
}

Published online: 21 November 2015

(c) The International Gastric Cancer Association and The Japanese Gastric Cancer Association 2015

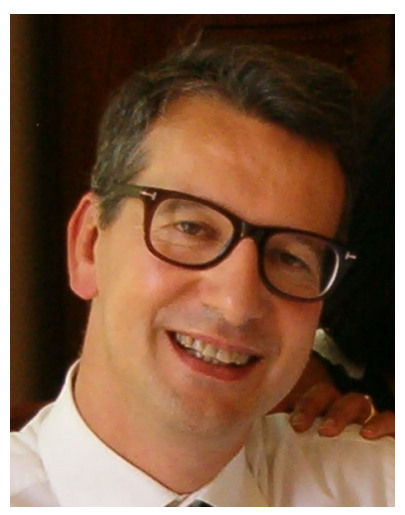

When the Council Board of the International Gastric Cancer Association asked me to represent the Western side of our society and to join Yuko Kitagawa as a co-editor-inchief of Gastric Cancer, I was very enthusiastic.

In recent years, a multidisciplinary approach to gastric cancer has become essential, and I strongly believe that our journal, focused on gastric cancer and covering all the different specialties, is very important to spread new achievements.

In gastric cancer treatment, Eastern and Western countries still have different approaches: not only the surgical approach, but also adjuvant and neoadjuvant choices change a lot according to the continent.

Publishing the most outstanding studies on gastric cancer will give us the possibility to compare results reported all over the world in terms of tumor biology, surgical approaches, and preoperative/postoperative treatment. I believe that soon this will be a way to enable us to understand better why there are differences in outcomes reported in Eastern and Western series. It will also be very important to encourage submissions dealing with esophagogastric junction cancer, a cancer with rising incidence.

By working hard with Yuko Kitagawa, I intend to maintain the excellent scientific level reached by the journal in recent years and to increase the number of contributions from the Western world.

Giovanni de Manzoni

giovanni.demanzoni@univr.it

1 Upper GI Surgery Division, University of Verona, Verona, Italy 